\title{
Tumor suppressor PLZF regulated by IncRNA ANRIL suppresses proliferation and epithelial mesenchymal transformation of gastric cancer cells
}

\author{
JUN-BIN WANG ${ }^{1,2^{*}}$, YAN JIN $^{3 *}$, PENG WU ${ }^{4}$, YANG LIU $^{5}$, WEN-JING ZHAO ${ }^{4}$, \\ JIN-FEI CHEN ${ }^{4}$, WEI DE ${ }^{2}$ and FEN YANG ${ }^{2}$ \\ ${ }^{1}$ Department of Oncology, The First Affiliated Hospital of Bengbu Medical College, Bengbu, Anhui 233004; \\ ${ }^{2}$ Department of Biochemistry and Molecular Biology, School of Basic Medical Sciences, \\ Nanjing Medical University, Nanjing, Jiangsu 211166; ${ }^{3}$ Department of Oncology, \\ The Affiliated Huaian No. 1 People's Hospital of Nanjing Medical University, Huaian, Jiangsu 223300; \\ ${ }^{4}$ Department of Oncology, Nanjing First Hospital, Nanjing Medical University, \\ Nanjing, Jiangsu 210006; ${ }^{5}$ Department of Clinical Pharmacy, School of Pharmacy, \\ Nanjing Medical University, Nanjing, Jiangsu 211166, P.R. China
}

Received June 6, 2018; Accepted November 1, 2018

DOI: $10.3892 / o r .2018 .6866$

\begin{abstract}
Promyelocytic leukemia zinc finger (PLZF) plays important roles in tumorigenic and developmental processes of various types of cancers. However, the expression of PLZF in gastric cancer (GC) has not been reported. The aim of the present study was to investigate the expression level and potential status of PLZF in GC as well as its possible mechanism. In the present study, we found that PLZF was downregulated in the majority of GC cell lines and tumor tissues and that alteration of PLZF expression was closely correlated with a malignant phenotype, epithelial-mesenchymal transformation and overall survival. Evaluation of in vitro proliferation, colony information, migration and invasion indicated that PLZF gene transduction induced a less malignant phenotype, which was also confirmed through in vivo studies performed
\end{abstract}

Correspondence to: Dr Fen Yang, Department of Biochemistry and Molecular Biology, School of Basic Medical Sciences, Nanjing Medical University, 101 Longmian Avenue, Jiangning, Nanjing, Jiangsu 211166, P.R. China

E-mail: yangfen@njmu.edu.cn

*Contributed equally

Abbreviations: PLZF, promyelocytic leukemia zinc finger; GC, gastric cancer; lncRNAs, long non-coding RNAs; ANRIL, CDKN2B antisense RNA 1; 5-Aza, 5-Aza-2'-deoxycytidine; PRC2, polycomb repressive complex 2; MSP, methylation-specific PCR; Xist, X-inactive specific transcript; EMT, epithelial-mesenchymal transformation; MET, mesenchymal-epithelial transformation; NSCLC, non-small cell lung cancer

Key words: PLZF, ANRIL, EMT, gastric cancer, methylation in athymic nude mice. Furthermore, we assessed the expression levels of the lncRNA ANRIL in GC and found that it was negatively associated with the level of PLZF and that ANRIL indirectly methylated PLZF to suppress its expression via binding with polycomb repressive complex 2 . When GC cells were treated with the methylation inhibitor 5-Aza-2'-deoxycytidine, the expression of PLZF increased, which further confirmed that PLZF was methylated. These results indicated that constitutive ANRIL activation was a possible cause of the lack of PLZF expression in GC cells. Coupled deregulation of PLZF and ANRIL may account for most of the alterations described in GC, and PLZF may become a potential target of GC therapy.

\section{Introduction}

Promyelocytic leukemia zinc finger (PLZF), also known as BTB-containing protein 16 (ZBTB16), was originally identified as a gene fused to RARa in acute promyelocytic leukemia patients (1). PLZF plays an important role in the developmental and biological processes of carcinogenesis, functioning as a tumor suppressor or promoter $(2,3)$. In early studies, PLZF expression was lost in cancer cells and the loss of PLZF expression was related to increased proliferation, invasiveness, motility and resistance to apoptosis $(2,4)$. However, with further investigation the role of PLZF appeared to be controversial in tumor progression. Except for hematological malignancies, PLZF has also been implicated in various solid tumors. The loss of PLZF expression in tumors compared with normal tissue has been observed in melanoma, hepatocellular carcinoma, pancreatic and lung cancer, thyroid carcinoma, prostate and gallbladder cancer (5-11), and increased PLZF expression in tumors has been observed in clear cell renal cell carcinoma, colon cancer, glioblastoma and testicular seminoma $(3,12)$. However, the expression and value of PLZF 
in gastric cancer (GC) have not been studied, and it is reasonable to think that PLZF may play an important role in GC. Furthermore, the exact reason for PLZF regulation in cancers is not well documented.

Long non-coding RNAs (lncRNAs) are a subset of non-coding RNAs that mediate their biological functions using chromatin as a substrate to interact with the genetic information encoded in the genome (13). Among lncRNAs, ANRIL (CDKN2B antisense RNA 1) is transcribed in the opposite direction from the INK4b-ARF-INK4a gene cluster, which has been identified as a shared genetic susceptibility locus associated with coronary disease, intracranial aneurysm, type 2 diabetes and cancers $(14,15)$. ANRIL can be induced by the ATM-E2F1 signaling pathway and is required for the silencing of p15INK4B by recruiting polycomb repressive complex 2 (PRC2) $(16,17)$.

$\mathrm{EZH} 2$, a subunit of PRC2, which plays important roles in epigenetic gene silencing by catalyzing di- and tri-methylation of $\mathrm{H} 3 \mathrm{~K} 27$ can recruit the DNA methyltransferases to a target promoter, resulting in DNA methylation and subsequent gene silencing $(18,19)$. DNA methylation patterns in CpG-rich promoter regions and $\mathrm{CpG}$ islands regulate gene expression in mammalian cells; usually, methylation of $\mathrm{CpG}$ dinucleotides in the promoter represses gene expression (20). Particularly in cancer, gene silencing occurs through aberrant methylation in the promoter of tumor suppressor genes (21).

It has been reported that both of PcG activity and DNA methylation contribute to epigenetic repression and there exists crosstalk between them. In the present study, we found that ANRIL expression in GC was negatively associated with the level of PLZF and with ANRIL-recruited PRC2, which then drove PLZF silencing by collaborating between H3K27me3 and DNA methylation. Evidence that the methylation inhibitor 5-Aza-2'-deoxycytidine (5-Aza) could increase the expression level of PLZF confirmed the regulatory methylation. Our results provide new insights into the expression level and potential status of PLZF in GC as well as a possible mechanism of alteration.

\section{Materials and methods}

Cell lines. The human GC cell lines SGC7901, BGC823, MGC803, MKN28 and MKN45 and the normal gastric epithelium cell line (GES1) were obtained from the Chinese Academy of Sciences Committee on Type Culture Collection Cell Bank (Shanghai, China) and Fuheng Cell Center (Shanghai, China). All cell lines were authenticated by STR profiling. Cell lines were cultured in Dulbecco's modified Eagle's medium supplemented with $10 \%$ fetal bovine serum (FBS) in a humidified atmosphere containing $5 \% \mathrm{CO}_{2}$ at $37^{\circ} \mathrm{C}$.

Study subjects. We obtained 60 paired GC and adjacent non-cancer tissues from patients who underwent surgery at Nanjing First Hospital of Jiangsu Province in China between 2011 and 2012 and who were diagnosed with GC based on histopathological evaluation. No local or systemic treatment was administered to these patients prior to surgery. All collected tissue samples were preserved in RNA Transport (OMEGA, Norwalk, CT, USA) and immediately frozen at $-80^{\circ} \mathrm{C}$ until required. The clinical characteristics of all patients
Table I. The relationship between PLZF expression and clinicopathological factors of GC patients.

\begin{tabular}{|c|c|c|c|}
\hline \multirow[b]{2}{*}{ Clinical parameters } & \multicolumn{2}{|c|}{ PLZF levels } & \multirow[b]{2}{*}{ P-value } \\
\hline & $\begin{array}{l}\text { High } \\
(n=10)\end{array}$ & $\begin{array}{c}\text { Low } \\
(n=50)\end{array}$ & \\
\hline Age, years & & & 0.540 \\
\hline$\leq 60$ & 2 & 18 & \\
\hline$>60$ & 8 & 32 & \\
\hline Sex & & & 0.723 \\
\hline Male & 6 & 30 & \\
\hline Female & 4 & 20 & \\
\hline Histologic differentiation & & & $0.002^{\mathrm{c}}$ \\
\hline Low or undifferentiation & 1 & 35 & \\
\hline Middle or high & 9 & 15 & \\
\hline Invasion depth & & & $0.006^{\mathrm{c}}$ \\
\hline $\mathrm{T} 1$ & 8 & 14 & \\
\hline $\mathrm{T} 2$ or above & 2 & 36 & \\
\hline TNM stages & & & $0.037^{\mathrm{b}}$ \\
\hline $\mathrm{I} / \mathrm{II}$ & 8 & 19 & \\
\hline III/IV & 2 & 31 & \\
\hline Lymphatic metastasis & & & $0.037^{\mathrm{b}}$ \\
\hline Yes & 0 & 20 & \\
\hline No & 10 & 30 & \\
\hline Distant metastasis & & & 0.278 \\
\hline Yes & 0 & 10 & \\
\hline No & 10 & 40 & \\
\hline
\end{tabular}

${ }^{\mathrm{a}} \mathrm{Chi}$-squared test; ${ }^{\mathrm{b}} \mathrm{P}<0.05$; ${ }^{\mathrm{c}} \mathrm{P}<0.01$. $\mathrm{PLZF}$, promyelocytic leukemia zinc finger; GC, gastric cancer; TNM, tumor-node-metastasis.

are listed in Table I. The present study was approved by the Ethics Committee of Nanjing Medical University.

Quantitative RT-PCR ( $q R T-P C R$ ). Total RNA was extracted from cultivated cells or tissue using TRIzol reagent (Invitrogen; Thermo Fisher Scientific, Inc., Waltham, MA, USA) according to the manufacturer's protocol. RNA concentrations were determined spectrophotometrically at $260 \mathrm{~nm}$. Total RNA $(1 \mu \mathrm{g})$ was reverse transcribed to cDNA in a total volume of $20 \mu \mathrm{l}$. Quantitative PCR was performed with the following thermocycling conditions: $95^{\circ} \mathrm{C} 30 \mathrm{sec}$ for initial denaturation, $95^{\circ} \mathrm{C} 5 \mathrm{sec}, 60^{\circ} \mathrm{C} 34 \mathrm{sec}$ for PCR reaction, 40 cycles, using a 7300 Plus Real-Time PCR System (Applied Biosystems; Thermo Fisher Scientific, Inc.) and SYBR Premix Ex Taq (Takara Biotechnology Co., Ltd., Dalian, Liaoning, China) as a DNA-specific fluorescent dye. Notably, cDNA synthesis of coding gene mRNA used PrimeScript ${ }^{\mathrm{TM}}$ RT reagent Kit (cat. no. RR037A; Takara Biotechnology Co., Ltd.) and cDNA synthesis of lncRNA used PrimeScript RT Reagent kit with gDNA Eraser (cat. no. RR047A; Takara Biotechnology Co., Ltd.). Gene expression levels were calculated relative to GAPDH and $\beta$-actin using the $2^{-\Delta \Delta \mathrm{Ct}}$ method (22). GAPDH 
Table II. Primers used for qRT-PCR and MPCR.

\begin{tabular}{|c|c|}
\hline Primers & Sequences \\
\hline PLZF-F & AGCGGTTCCTGGATAGTTT \\
\hline PLZF-R & ATGCGTTTGTGGCTCTTG \\
\hline Methylated PLZF-F & $\begin{array}{l}\text { TCGTTAGTATTAAAGATGGAGA } \\
\text { GGC }\end{array}$ \\
\hline Methylated PLZF-R & $\begin{array}{l}\text { GAAATTAACAAATCACCACC } \\
\text { GAC }\end{array}$ \\
\hline Unmethylated PLZF-F & $\begin{array}{l}\text { GGTTGTTAGTATTAAAGATGGA } \\
\text { GAGGT }\end{array}$ \\
\hline Unmethylated PLZF-R & $\begin{array}{l}\text { CTACAAAATTAACAAATCACCA } \\
\text { CCA }\end{array}$ \\
\hline ANRIL-F & TGCTCTATCCGCCAATCAGG \\
\hline ANRIL-R & GCGTGCAGCGGTTTAGTTT \\
\hline E-cadherin-F & GAACGCATTGCCACATACAC \\
\hline E-cadherin-R & GAGGATGGTGTAAGCGATGG \\
\hline N-cadherin-F & ATGGAAGGCAATCCCACATA \\
\hline N-cadherin-R & CAGTAGGATCTCCGCCACTG \\
\hline Vimentin-F & GTACCGGAGACAGGTGCAGT \\
\hline Vimentin-R & CTCAATGTCAAGGGCCATCT \\
\hline EZH2-F & ACATCCTTTTCATGCAACACC \\
\hline EZH2-R & GCTCCCTCCAAATGCTGGTA \\
\hline SUZ12-F & ACATCAAAAGCTTGTCAGCTC \\
\hline SUZ12-R & GCACCTGCTTTTTACCTGTGG \\
\hline Snail-F & CAAGATGCACATCCGAAGCC \\
\hline Snail-R & CATCTGAGTGGGTCTGGAGG \\
\hline Slug-F & GCTACCCAATGGCCTCTCTC \\
\hline Slug-R & СTTCAATGGCATGGGGGTCT \\
\hline ZEB1-F & GATGACCTGCCAACAGACCA \\
\hline ZEB1-R & CCCCAGGATTTCTTGCCCTT \\
\hline GAPDH-F & AGCCACATCGCTCAGACAC \\
\hline GAPDH-R & GCCCAATACGACCAAATCC \\
\hline$\beta$-actin-F & CTGGGACGACATGGAGAAAA \\
\hline$\beta$-actin-R & AAGGAAGGCTGGAAGAGTGC \\
\hline MEG3-F & GTGGAAGCACGCTCACAAAG \\
\hline MEG3-R & GAAGACTTGGGTCCGGGATG \\
\hline TUG1-F & $\begin{array}{l}\text { CAAGAAACAGCAACACCAG } \\
\text { AAG }\end{array}$ \\
\hline TUG1-R & TAAGGTCCCCATTCAAGTCAGT \\
\hline LINC00152-F & TTGATGGCTTGAACATTTGG \\
\hline LINC00152-R & TCGTGATTTTCGGTGTCTGT \\
\hline H19-F & GCCTTGACGTGCTGGATCT \\
\hline H19-R & $\begin{array}{l}\text { TCCGATGCTTTACTCAAGAA } \\
\text { GTT }\end{array}$ \\
\hline HOTAIR-F & $\begin{array}{l}\text { GCGCTGCAAGTGCTTACTGT } \\
\text { GCA }\end{array}$ \\
\hline HOTAIR-R & CCGAGGTATTCGCACTGGATAC \\
\hline PVT1-F & CAGTGGGGAACTCTGACTCG \\
\hline PVT1-R & GTGCCTGGTGCTCTCTTACC \\
\hline LINC00261-F & ATCAAGAGGCAATGGTCCCA \\
\hline LINC00261-R & TTCAGCTCTTAGGGCAGGAC \\
\hline SNHG1-F & AGGCTGAAGT TACAGGTC \\
\hline SNHG1-R & TTGGCTCCCAGTGTCTTA \\
\hline UCA1-F & AGTGGCTGAAGACTGATGC \\
\hline
\end{tabular}

Table II. Continued.

\begin{tabular}{ll}
\hline Primers & \multicolumn{1}{c}{ Sequences } \\
\hline UCA1-R & AGATGGACGGCAGTTGGT \\
GAS5-F & CCCAAGGAAGGATGAG \\
GAS5-R & ACCAGGAGCAGAACCA \\
SPRY4-IT1-F & AGCCACATAAATTCAGCAGA \\
SPRY4-IT1-R & CGATGTAGTAGGATTCCTTTCA \\
\hline
\end{tabular}

F, forward; R, reverse.

Table III. siRNA sequences of targets.

\begin{tabular}{ll}
\hline Targets & \multicolumn{1}{c}{ siRNA sequences } \\
\hline EZH2 & AUCAGCUCGUCUGAACCUCUU \\
MEG3 & UCCCUCUUACCUAAAGACUUAAA \\
TUG1 & CAGUCCUGGUGAUUUAGACAGUCUU \\
LINC00152 & UGAUCGAAUAUGACAGACACCGAAA \\
H19 & CCCACAACAUGAAAGAAACTT \\
HOTAIR & GCAACCTAAACCAGCAATT \\
PVT1 & GCUUGGAGGCUGAGGAGUUTT \\
LINC00261 & CAGTCGCTTGGTTTGAGCTCAAATA \\
SNHG1 & CAGCAGT TGAGGGTTTGCTGTGTAT \\
UCA1 & GCCATATGAAGACACCCTA \\
GAS5 & CTTGCCTGGACCAGCTTAATT \\
SPRY4-IT1 & GCTTTCTGATTCCAAGGCCTATTAA \\
siCtrl & GCATCAACAACCGAACATT \\
\hline
\end{tabular}

and $\beta$-actin were used as endogenous controls. The primer sequences are listed in Table II.

Plasmid, siRNA and transfection. PLZF (ZBTB16) (NM_006006) Human Tagged ORF Clone (cat. no. RG206745) and pCMV6-AC-GFP Tagged Cloning Vector (cat. no. PS100010) were purchased from OriGene Technologies, Inc. (Rockville, MD, USA). Plasmid vectors for transfection were prepared using DNA Midiprep Kits (Qiagen, Duesseldorf, NRW, Germany) and transfected into GC cells using Lipofectamine 2000 (Invitrogen; Thermo Fisher Scientific, Inc.). The siRNAs were synthesized by Invitrogen and transfected into GC cells using Lipofectamine 2000 according to the manufacturer's instructions. Cells were seeded at $\sim 2-4 \times 10^{5}$ cells/well in 6-well plates and transfected with $100 \mathrm{nmol} / \mathrm{l}$ siRNAs in Opti-MEM medium using Lipofectamine 2000 reagent. The cells were then allowed to reach $\sim 50 \%$ confluence on the day of transfection. The cells were switched into medium containing 10\% FBS after transfection for $\sim 4-6 \mathrm{~h}$ and incubated for another $\sim 24-48 \mathrm{~h}$ until extraction for the assessment of interfering efficiencies and targeted genes. All siRNA sequences are listed in Table III.

Cell proliferation, migration and invasion. The cell proliferation ability was examined using the CellTiter $96^{\circledR}$ AQueous One Solution Cell Proliferation Assay (MTS; Promega 
Corporation, Madison, WI, USA). Absorbance values were assessed at a wavelength of $570 \mathrm{~nm}$. Colony formation assays were performed to monitor the cloning capability of $\mathrm{GC}$ cells. The wound healing assay was used to evaluate the cell migration capabilities. The Transwell assay was performed to assess invasion. Procedural details were previously described (23).

Establishment of xenografts and in vivo study. Four-week-old female athymic BALB/c nude mice were maintained under specific pathogen-free conditions, using a 10-h light/14-h dark cycle at temperature of $25 \pm 1^{\circ} \mathrm{C}$ and relative humidity of 40 60\% with free access to food and water, and manipulated according to protocols approved by the Ethics Committee of Animal Experiments of the Nanjing Medical University. The mice were divided into two groups of the PLZF and the empty vector with 5 mice/group. PLZF and empty vector stably transfected SGC7901 cells were harvested and $10^{7}$ cells were subcutaneously injected into a single side of each mouse. Tumor sizes were measured by calipers and recorded every 3 days. The tumor volumes were calculated from the length (the longest diameter across the tumor) and width (the corresponding perpendicular diameter) using the following formula: $\pi / 6 \times$ length $x$ width $^{2}$. Twenty days later, the animals were sacrificed by carbon dioxide, and tumors were harvested and preserved at $-80^{\circ} \mathrm{C}$ and fixed in formaldehyde for qRT-PCR and immunohistochemistry (IHC) staining, respectively.

Western blot analysis. Western blot analysis was performed according to standard protocols as previously described (24). The primary antibodies of H3K27me3 (cat. no. 9733), EZH2 (cat. no. 5246), PLZF (cat. no. 39784) and GAPDH (cat. no. 5174) and the secondary antibody of HRP-linked anti-rabbit IgG (cat. no. 7074) were purchased from Cell Signaling Technology, Inc. (Danvers, MA, USA). The primary antibodies were diluted at 1:500-1,000 and incubated at $4^{\circ} \mathrm{C}$ overnight and the secondary antibody was diluted at 1:2,000 at room temperature for $2 \mathrm{~h}$.

Methylation-specific PCR (MSP). DNA is modified by sodium bisulfite treatment converting unmethylated, but not methylated, cytosines to uracil. Following the removal of bisulfite and completion of the chemical conversion, this modified DNA is used as a template for PCR. Primers were designed to discriminate between methylated and unmethylated alleles following bisulfite treatment and to discriminate between DNA modified (vs. unmodified) by bisulfite. The primer sequences of methylated and unmethylated PLZF are listed in Table II.

Bioinformatics analysis. RNA-Protein Interaction Prediction (RPISeq) (http://pridb.gdcb.iastate.edu/RPISeq/) was used to analyze the interaction of ANRIL and PLZF. In the RPISeq website, the sequences of ANRIL and PLZF were copied into the designated spaces and submitted to the system, and then the interaction probability was revealed. Interaction probabilities generated by RPISeq range from 0 to 1 . In performance evaluation experiments, predictions with probabilities $>0.5$ were considered 'positive', indicating that the corresponding RNA and protein are likely to interact.
RNA immunoprecipitation. The EZMagna RNA immunoprecipitation (RIP) Kit (EMD Millipore, Billerica, MA, USA) was performed based on the manufacturer's protocol. Cells were lysed in complete RIP lysis buffer (containing cOmplete $^{\mathrm{TM}}$ Protease Inhibitor Cocktail, Roche, Branford, CT, USA). The lysis mixture was incubated with magnetic beads conjugated with specific antibodies or control IgG overnight at $4^{\circ} \mathrm{C}$. Beads were washed and incubated with proteinase $\mathrm{K}$ to remove unconjugated proteins. Finally, RNAs were purified and subjected to qRT-PCR assay to analyze possible RNAs.

Chemical treatment. 5-Aza (cat. no. S1200) and suberoylanilide hydroxamic acid (SAHA) (cat. no. S1047) were purchased from Selleck Chemicals (Houston, TX, USA) and dissolved in dimethylsulphoxide (DMSO), and used at 10 and $2 \mu \mathrm{M}$, respectively. Subconfluent cell cultures were treated with 5-Aza and SAHA for $48 \mathrm{~h}$ and then extracted for MPCR and western blot analysis.

Statistical analysis. All results were represented as the mean \pm standard deviation (SD) from at least 3 independent experiments. Differences were determined by the two-tailed Student's t-test (comparison for two groups) and the one-way ANOVA (comparison for $>2$ groups) and the Tukey's post hoc test for multiple comparisons. Pearson's Chi-squared test was used to analyze the pathological features of PLZF expression in GC. Survival curves were drawn using a Kaplan-Meier survival plot and assessed using log-rank tests. Cox regression analysis was used to perform univariate and multivariate analyses of the clinicopathological factors for disease-free survival. All statistical analyses were performed using SPSS 19.0 software (IBM Corp., Armonk, NY, USA).

\section{Results}

PLZF is downregulated in the majority of GC cells. We evaluated PLZF expression in the normal human gastric epithelial cell line GES1 and in a panel of GC cell lines, and we found that PLZF had low expression in all the examined GC cell lines even after 40 cycles of amplification and western blot analysis, whereas it was expressed in the normal epithelial cell line at both the mRNA and protein levels (Fig. 1).

Overexpression of PLZF inhibits the proliferation, migration and invasion of GC cells. To determine the role of PLZF in GC, we monitored the effect of PLZF overexpression on GC cell lines. Fig. 2A revealed the efficiencies of PLZF overexpression. PLZF overexpression inhibited the viability of BGC823 and SGC7901 cells (Fig. 2B). Similarly, PLZF overexpression alleviated clone formation in BGC823 and SGC7901 cells (Fig. 2C). Transwell assay revealed that the number of invaded cells in the control group were higher than those in the PLZF overexpression group (Fig. 2D). In the wound healing assay, PLZF overexpression suppressed wound healing in both BGC823 and SGC7901 cells (Fig. 2E). Collectively, these findings indicated that increased PLZF expression in GC inhibited GC cell proliferation, migration and invasion.

Overexpression of PLZF suppresses the proliferation of nude mouse xenografts. In nude mouse xenografts, SGC7901 cells 
A

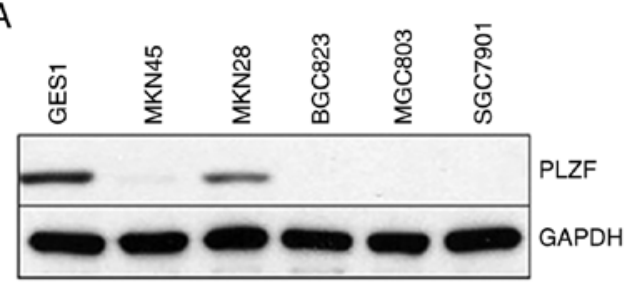

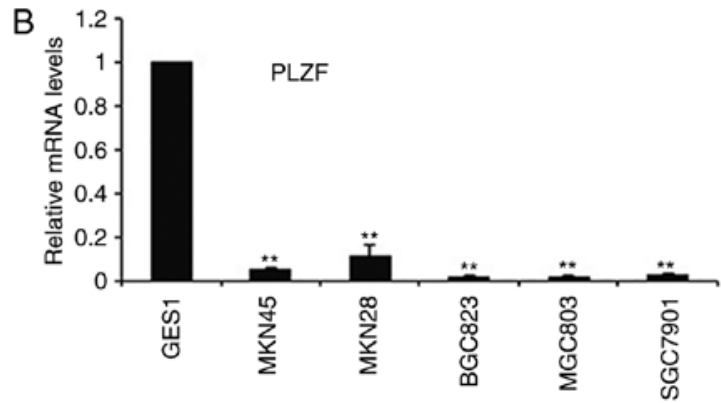

Figure 1. PLZF is downregulated in the majority of GC cells. (A) Relative protein levels of PLZF in a panel of GC cells were assessed by western blot analysis (B) Relative mRNA levels of PLZF in a panel of GC cells were determined by qRT-PCR. ${ }^{* *} \mathrm{P}<0.01$ for GC cells vs. GES1. Error bars indicated the means \pm SD from three independent experiments. PLZF, promyelocytic leukemia zinc finger; GC, gastric cancer; GES1, gastric epithelium cell line.
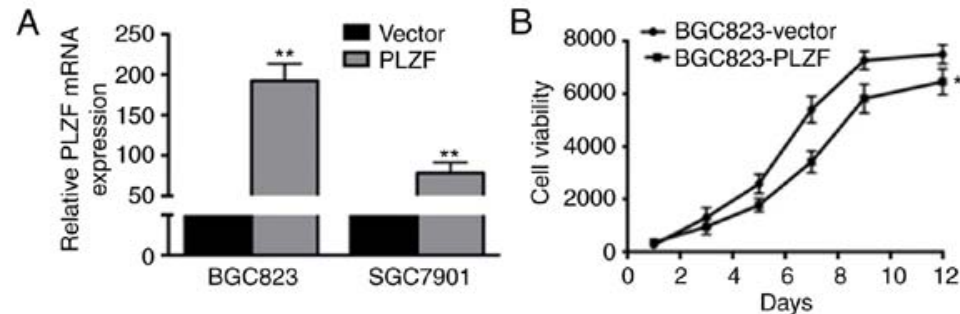

C
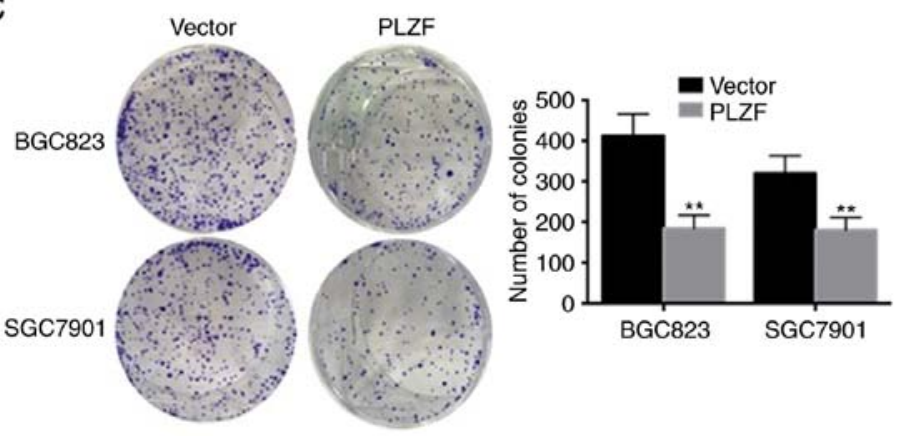

E

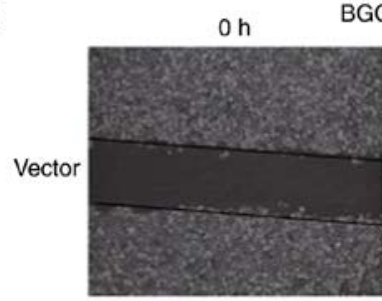

BGC823
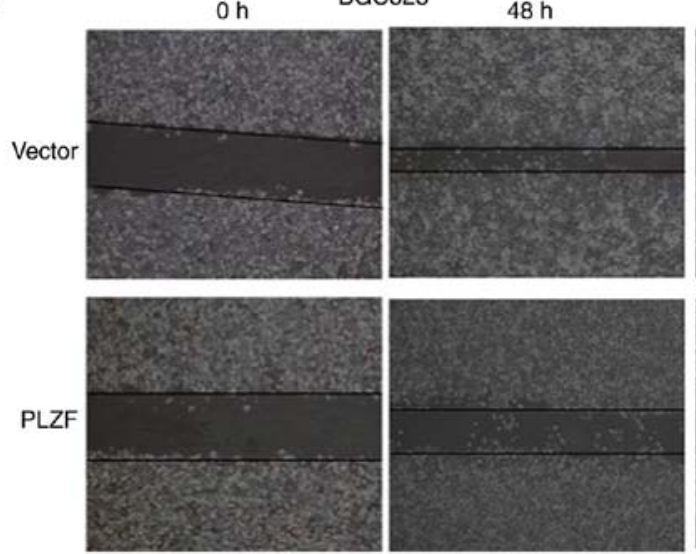

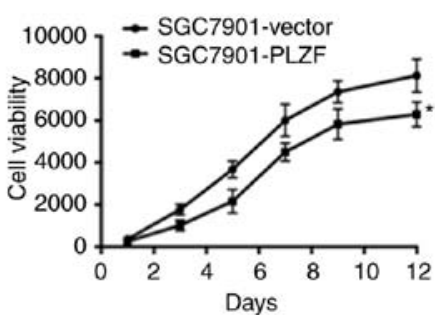

D
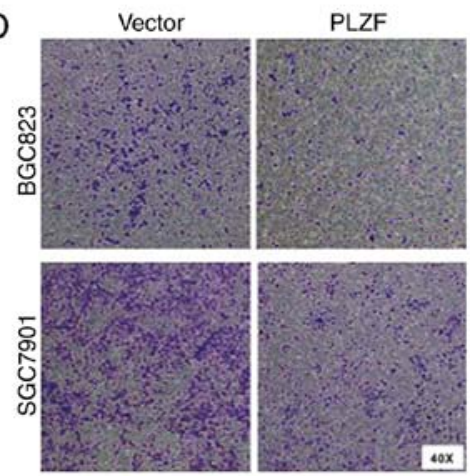

SGC7901
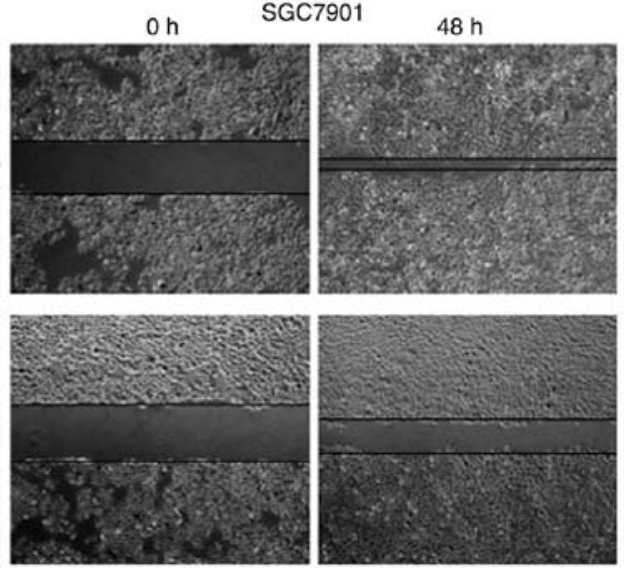

Figure 2. Overexpression of PLZF inhibits the proliferation, migration and invasion of GC cells. (A) Transfected efficiencies of overexpressed PLZF in SGC7901 and BGC823 cells. (B) Cellular proliferation was determined by the MTS assay after SGC7901 and BGC823 cells were stably transfected with PLZF plasmid and vectors. (C) The representative results from 3 independent experiments and statistical data of colony formation assays using SGC7901 and BGC823 cells stably transfected with PLZF plasmid and vectors. (D) Cell invasion was assessed by Transwell assay, and cell lines were treated the same as aforementioned. (E) Cell migration was monitored by the wound healing assay, and cell lines were treated the same as aforementioned. $\mathrm{P}<0.05$ and ${ }^{* *} \mathrm{P}<0.01$ for cells transfected with PLZF plasmid vs. cells transfected with vectors. Error bars indicated the means \pm SD from 3 independent experiments. PLZF, promyelocytic leukemia zinc finger; GC, gastric cancer.

stably transfected with the PLZF plasmid were inoculated into the flanks of mice, and SGC7901 cells stably transfected with the empty vector were also inoculated into the flanks of mice as a control. The efficiencies of PLZF overexpression were 


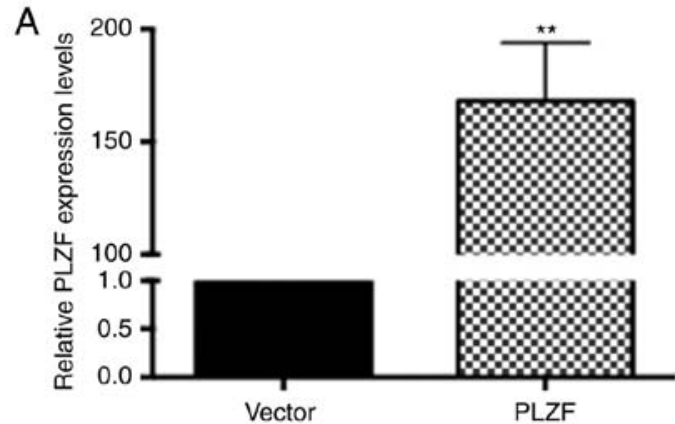

C
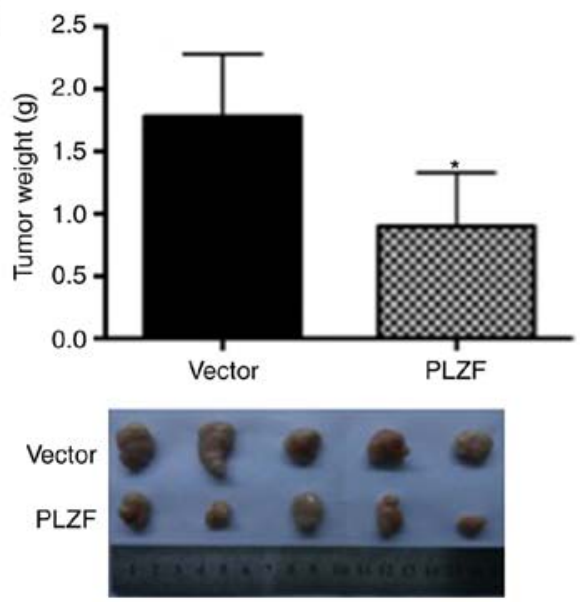

D
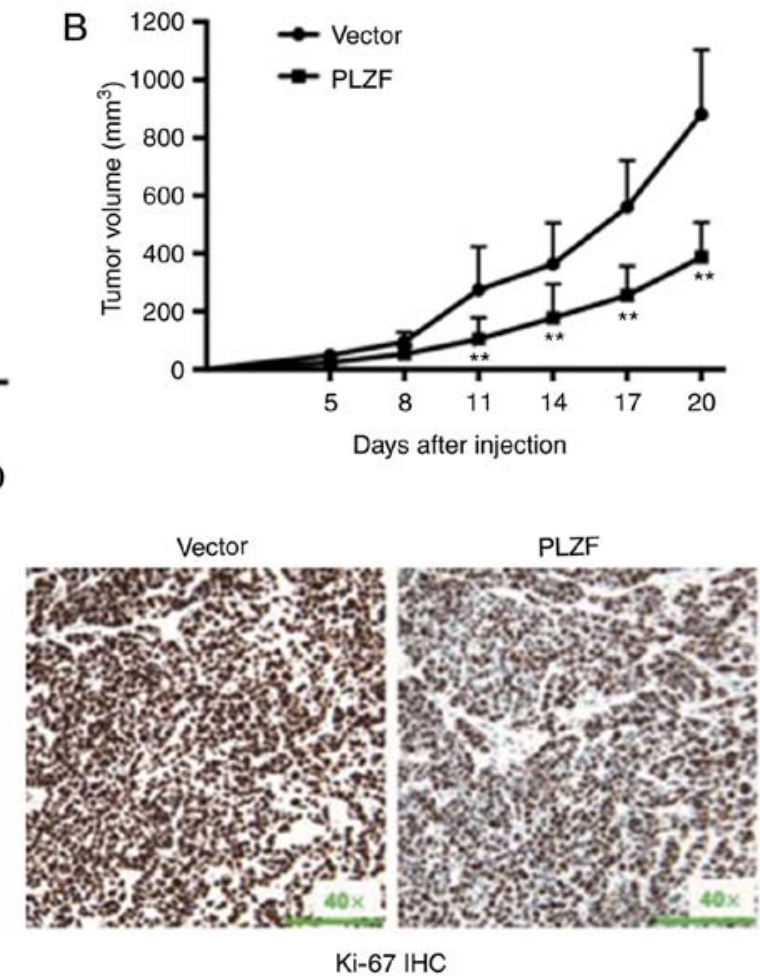

$\mathrm{Ki}-67 \mathrm{IHC}$

Figure 3. Lack of PLZF expression promotes the proliferation of GC cells in vivo. (A) Transfection efficiencies of overexpressed PLZF in SGC7901 cells. (B) SGC7901 cells stably transfected with PLZF plasmid and vectors were injected into nude mice $(\mathrm{n}=5)$ that were sacrificed by carbon dioxide euthanasia on 20th day after injection. Tumor volumes were calculated every 3 days beginning 5 days after injection. (C) Tumor weights were represented as the means of tumor weights $\pm \mathrm{SD}$. (D) The tumor sections underwent IHC staining using antibodies against Ki-67. ${ }^{*} \mathrm{P}<0.05$ and ${ }^{* *} \mathrm{P}<0.01$ for cells transfected with PLZF plasmid vs. cells transfected with vectors. Error bars indicated the means \pm SD. PLZF, promyelocytic leukemia zinc finger; GC, gastric cancer; IHC, immunohistochemistry.

assessed by qRT-PCR and presented in Fig. 3A. PLZF overexpression significantly inhibited tumorigenesis in vivo given that the tumor weight and size were significantly decreased compared with those of the controls (Fig. 3B and C). Furthermore, we detected stronger Ki-67 expression in tumors derived from control nude mice than in those derived from PLZF overexpression (Fig. 3D).

Negative association of PLZF and ANRIL in GC cells. By acting as oncogenes or tumor suppressors, many lncRNAs contribute to cancer occurrence and development by epigenetically regulating gene expression (25). We screened a panel of IncRNAs to search for the associated lncRNA of PLZF expression and found that both ANRIL and HOTAIR knockdown recovered the expression of PLZF in BGC823 cells (Fig. 4A and B). Since ANRIL knockdown increased PLZF expression more than HOTAIR knockdown, we chose ANRIL to further study PLZF regulation. Furthermore, we confirmed the negative association between PLZF and ANRIL expression in BGC823 and SGC7901 cells; ANRIL knockdown increased the expression of PLZF in both BGC823 and SGC7901 cells (Fig. 4C and D).

The interaction of ANRIL and PLZF induces DNA methylation of PLZF. To verify crosstalk between ANRIL and PLZF, we performed bioinformatics analysis and found that PLZF could possibly interact with ANRIL. In our analysis, the RF classifier was 0.7 , and the SVM classifier was 0.99; both were larger than 0.5 . In our study, efficiencies of PLZF overexpressed cell lines were presented in Fig. 5A and B. RIP experiment confirmed the interaction between ANRIL and PLZF in GC cells (Fig. 5C). Recent discoveries have marked lncRNAs as new important players in DNA methylation regulation (26). Therefore, we inferred that ANRIL may regulate PLZF methylation by binding to PRC2. MSP is a method for analyzing DNA methylation patterns in $\mathrm{CpG}$ islands, and it revealed that PLZF was methylated in BGC823 and SGC7901 cells, not in the normal cell lines GES1 (Fig. 5D). BGC823 and SGC7901 cells were treated with the methylation inhibitor 5-Aza, DNA methylation of PLZF was decreased (Fig. 5E), but PLZF expression was increased (Fig. 5F). In addition, the histone deacetylase (HDAC) inhibitor SAHA did not have the same effect, which suggested that PLZF was methylated, not acetylated (Fig. 5F).

PLZF is negatively associated with EZH2 and H3K27me3. It has been reported that ANRIL strongly enriches PRC2, which was confirmed (Fig. 6A) (27). To further investigate the relationship between PLZF and PRC2, we assessed the expression levels of EZH2 and $\mathrm{H} 3 \mathrm{~K} 27 \mathrm{me} 3$. We found that EZH2 and H3K27me3 were highly expressed in GC cell lines compared to that in the normal cell line GES1, which suggested that EZH2 and $\mathrm{H} 3 \mathrm{~K} 27 \mathrm{me} 3$ were negatively associated with PLZF (Fig. 6B and C). Moreover, upon EZH2 

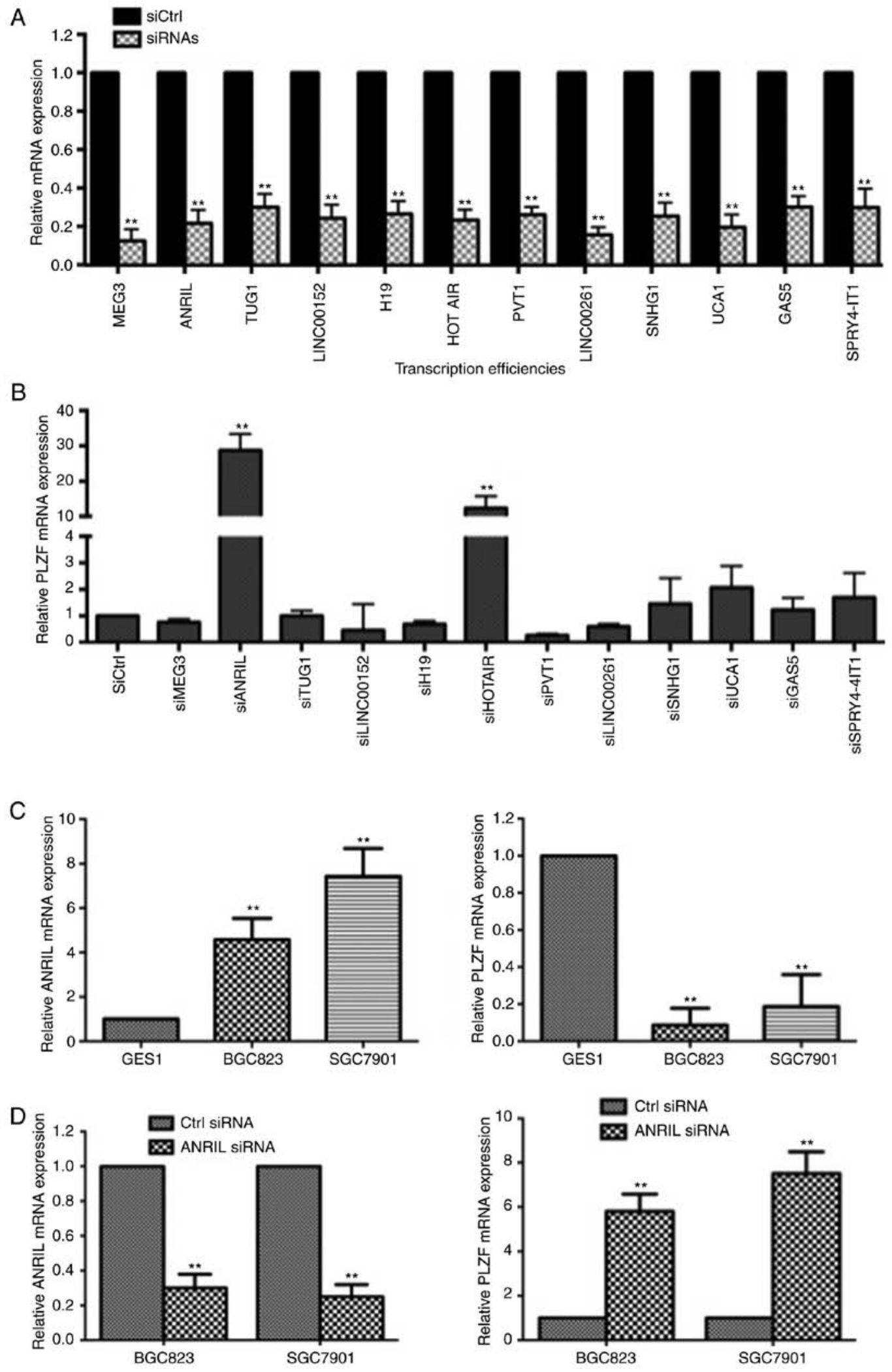

Figure 4. Negative association of PLZF and ANRIL in GC cells. (A) Transfection efficiencies of a panel of lncRNA siRNAs were tested by qRT-PCR in BGC823 cells. (B) The effects of knockdown of a panel of lncRNAs on the expression of PLZF mRNA. (C) Negative association between PLZF and ANRIL in SGC7901 and BGC823 cells. The left panel represents the relative expression of ANRIL mRNA, and the right panel represents the relative expression of PLZF mRNA. (D) The effect of ANRIL knockdown on the expression of PLZF mRNA was confirmed. The left panel indicates the ANRIL siRNA transfection efficiency, and the right panel indicates the expression of PLZF mRNA upon ANRIL knockdown. ${ }^{* *} \mathrm{P}<0.01$. Error bars indicate the means \pm SD from 3 independent experiments. PLZF, promyelocytic leukemia zinc finger; ANRIL, CDKN2B antisense RNA 1; GC, gastric cancer; lncRNAs, long non-coding RNAs.

knockdown by siRNA transfection, PLZF expression was markedly increased (Fig. 6D and E), confirming that PLZF was negatively associated with EZH2 and H3K27me3. Therefore, we concluded that ANRIL regulated PLZF 
A

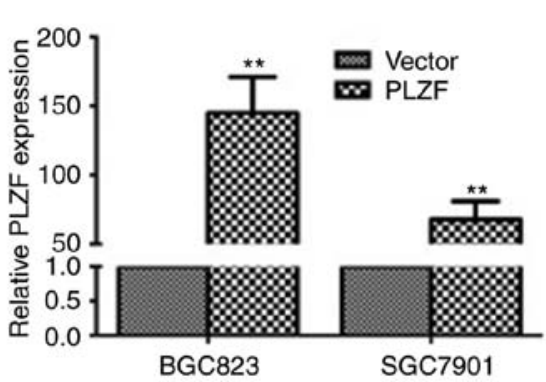

C

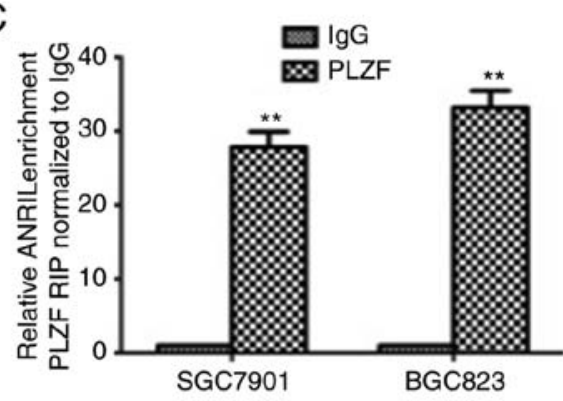

E

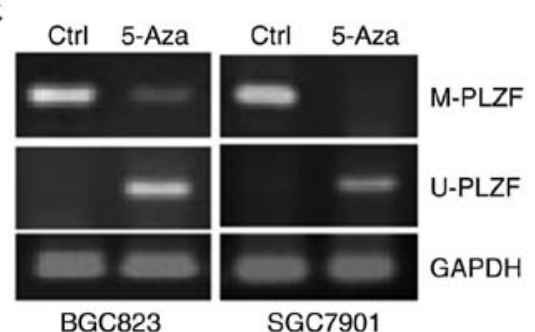

B

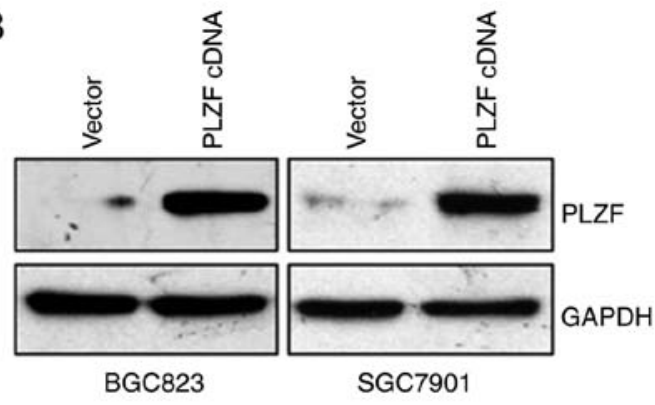

D

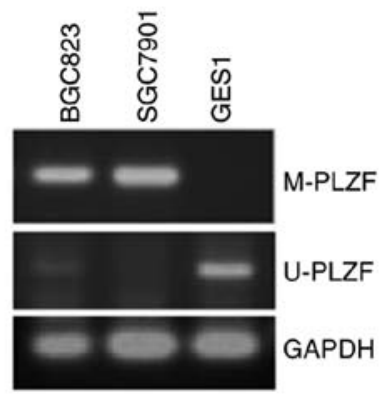

$\mathrm{F}$

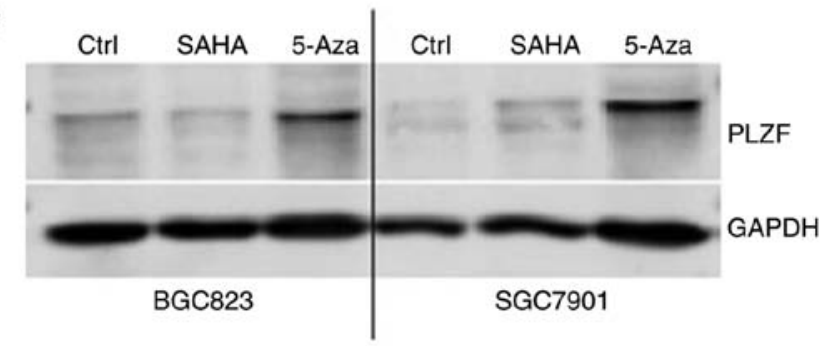

Figure 5. ANRIL induces DNA methylation of PLZF. (A) Transfection efficiencies of overexpressed PLZF in BGC823 and SGC7901 cells were determined by qRT-PCR. (B) Transfection efficiencies were analyzed by western blot analysis. (C) Relative ANRIL enrichment was assessed by the RIP experiment using PLZF antibody with an IgG antibody as a control. (D) Methylated PLZF was assessed by MPCR using methylated PLZF primers and unmethylated PLZF primers in GC cells BGC823 and SGC7901 and normal cells GES1. (E) BGC823 and SGC7901 cells were treated with 5-Aza and methylated PLZF was reduced. (F) In BGC823 and SGC7901 cells, the protein levels of PLZF were analyzed by western blot analysis after SAHA and 5-Aza treatments for $48 \mathrm{~h}$. ${ }^{* *} \mathrm{P}<0.01$. Error bars indicate the means \pm SD from 3 independent experiments. ANRIL, CDKN2B antisense RNA 1; PLZF, promyelocytic leukemia zinc finger; GC, gastric cancer; GES1, gastric epithelium cell line.
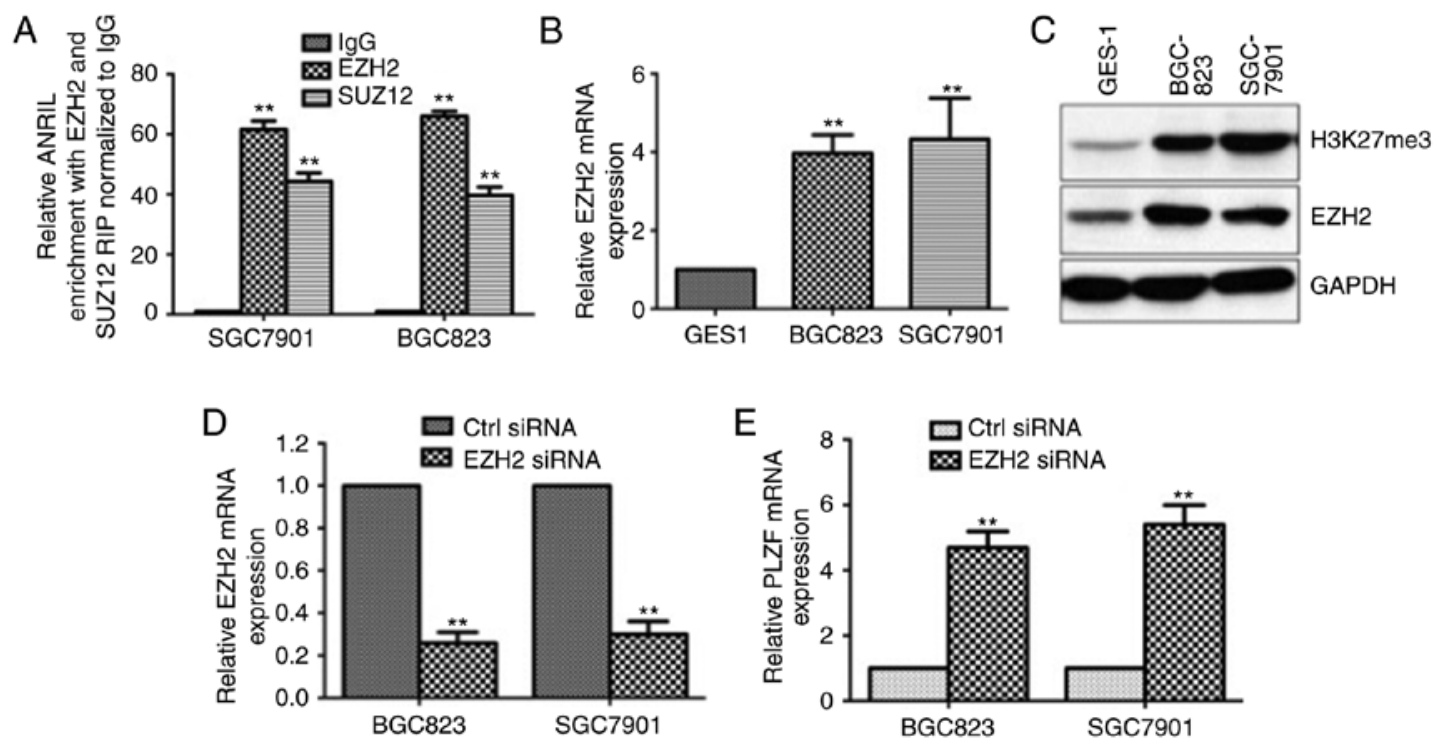

Figure 6. PLZF is negatively associated with EZH2 and H3K27me3 in GC cells. (A) Relative ANRIL enrichment was assessed by an RIP experiment using PRC2 component EZH2 and SUZ12 antibodies with an IgG antibody as a control. (B) Relative mRNA level of EZH2 was confirmed by qRT-PCR in GC and control cells. (C) Protein levels of EZH2 and H3K27me3 were analyzed by western blot analysis. (D) Transfection efficiency of EZH2 siRNA. (E) Relative expression of PLZF upon EZH2 knockdown. ${ }^{* *} \mathrm{P}<0.01$. Error bars indicate the means \pm SD from 3 independent experiments. PLZF, promyelocytic leukemia zinc finger; GC, gastric cancer. 

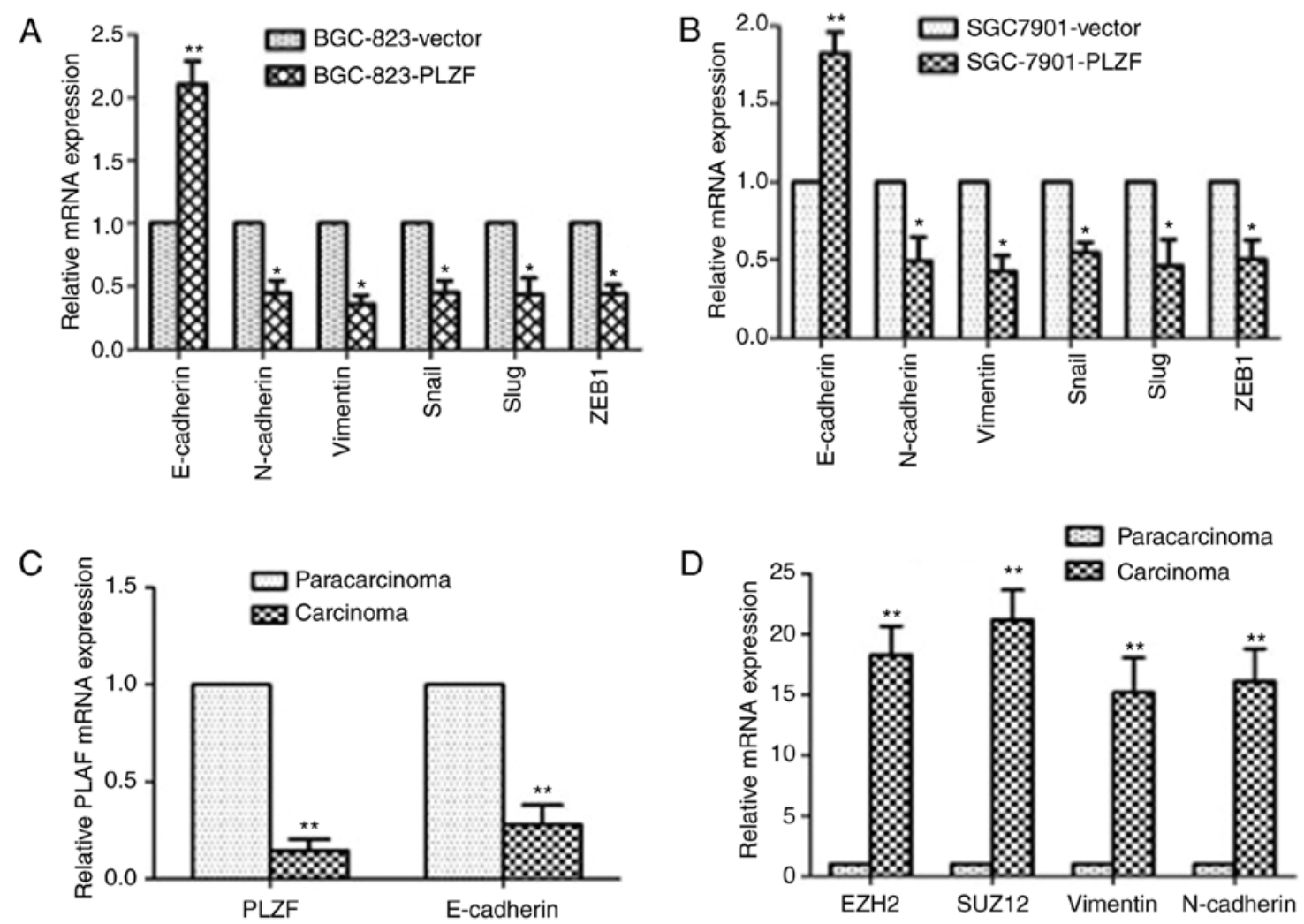

\section{$\mathrm{E}$}
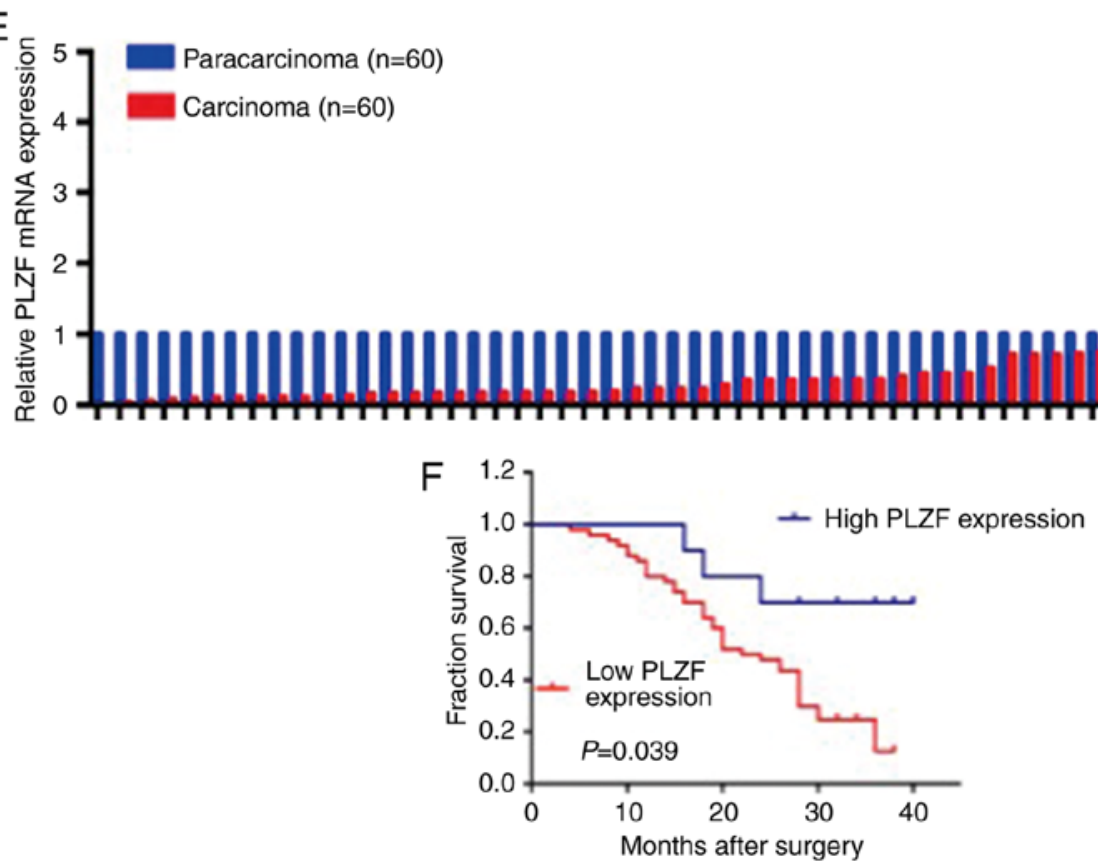

Figure 7. Absence of PLZF induces EMT of GC cells and is correlated with poor prognosis. (A) Relative expression of EMT markers in BGC823 cells stably transfected with PLZF plasmid and vectors. (B) Relative expression of EMT markers in SGC7901 cells stably transfected with PLZF plasmid and vectors. (C) Relative mRNA expression of PLZF and epithelial marker E-cadherin in GC tissues with paracarcinoma tissue as a control. (D) Relative mRNA expression of PRC2 components and mesenchymal markers in GC tissues with paracarcinoma tissue as a control. (E) Relative mRNA expression of PLZF in GC tissues with corresponding paracarcinoma tissues as controls $(n=60)$. (F) Survival times of patients with low PLZF expression were decreased compared to those of patients with high PLZF expression. ${ }^{*} \mathrm{P}<0.05$ and ${ }^{* *} \mathrm{P}<0.01$. Error bars indicate the means $\pm \mathrm{SD}$ from 3 independent experiments. PLZF, promyelocytic leukemia zinc finger; EMT, epithelial- mesenchymal transformation; GC, gastric cancer.

level through collaboration between DNA methylation and H3K27me3.

Absence of PLZF modulates epithelial-mesenchymal transformation (EMT) of GC cells and is correlated with poor prognosis. To investigate the effect of PLZF on EMT, we identified EMT markers in the PLZF-overexpressed GC cell lines BGC823/PLZF and SGC7901/PLZF. The results revealed that the epithelial marker E-cadherin was enhanced and that the mesenchymal markers N-cadherin, vimentin, Snail, Slug 
Table IV. Univariate and multivariate Cox regression analyses for disease-free survival of 60 patients with GC.

\begin{tabular}{|c|c|c|c|}
\hline \multirow[b]{2}{*}{ Risk factors } & \multicolumn{3}{|c|}{ DFS } \\
\hline & HR & $95 \%$ CI & P-value \\
\hline \multicolumn{4}{|l|}{ Univariate analysis } \\
\hline Age ( $\leq 60$ years, $>60$ years $)$ & 2.199 & $1.124-4.302$ & $0.021^{\mathrm{a}}$ \\
\hline Sex (male, female) & 0.661 & $0.347-1.259$ & 0.208 \\
\hline PLZF expression & 0.049 & $0.010-0.244$ & $0.000^{\mathrm{b}}$ \\
\hline Histological grade (low or undifferent, middle or high) & 1.797 & $0.943-3.426$ & 0.075 \\
\hline Lymph node metastasis (yes or no) & 2.221 & $1.152-4.281$ & $0.017^{\mathrm{a}}$ \\
\hline Tumor invasion depth (T1, T2 or above) & 5.906 & $2.761-12.632$ & $0.000^{\mathrm{b}}$ \\
\hline TNM stage (I/II, III/IV) & 1.925 & $0.851-4.353$ & 0.116 \\
\hline Distant metastasis (yes or no) & 4.760 & $2.303-9.838$ & $0.000^{\mathrm{b}}$ \\
\hline \multicolumn{4}{|l|}{ Multivariate analysis } \\
\hline PLZF expression & 0.087 & $0.018-0.421$ & $0.002^{\mathrm{b}}$ \\
\hline Distant metastasis (yes or no) & 2.355 & $1.089-5.094$ & $0.030^{\mathrm{a}}$ \\
\hline
\end{tabular}

GC, gastric cancer; DFS, disease-free survival; HR, hazard ratio; CI, confidence interval; PLZF, promyelocytic leukemia zinc finger; TNM, tumor-node-metastasis. ${ }^{\mathrm{a}} \mathrm{P}<0.05 ;{ }^{\mathrm{b}} \mathrm{P}<0.01$.

and ZEB1 were reduced compared to those in GC cells transfected with the empty vector (Fig. 7A and B). In GC patient tissue samples, we found that PLZF and E-cadherin expression levels in carcinoma tissues had parallel trends and were less than those in adjacent non-cancer tissues, while EZH2, SUZ12, vimentin and $\mathrm{N}$-cadherin expression levels in carcinoma tissues were higher than those in adjacent non-cancer tissues (Fig. 7C and D). These results indicated that the level of PLZF expression contributed to mesenchymal-epithelial transformation (MET).

To validate the differential expression of PLZF in GC patients, we assessed the PLZF expression levels in tissue samples from $60 \mathrm{GC}$ patients by qRT-PCR assay. Relative PLZF mRNA expression was assessed and normal adjacent non-cancer tissue was presented as 1. PLZF expression of cancer tissue was normalized to the adjacent non-cancer tissue, and a ratio $<1$ represented a low PLZF level, while a ratio of $>1$ represented a high PLZF level. The results revealed that PLZF expression was significantly lower in cancer tissues than in adjacent normal tissues (Fig. 7E). By analyzing clinicopathological factors, we found that the low PLZF expression was correlated with poor prognosis in GC patients (Fig. 7F). The PLZF levels were also correlated with histological differentiation, tumor invasion depth, tumor-node-metastasis (TNM) stage and lymphatic metastasis. No relation was found between PLZF expression and other factors, e.g., sex, age and distant metastasis (Table I). Multivariate analysis further revealed that PLZF expression could be regarded as a potential diagnostic biomarker for disease-free survival in patients with GC, as well as distant metastasis (Table IV).

\section{Discussion}

GC is ranked as the fifth most common malignant neoplasm in the world, with approximately 951,600 new diagnoses and 723,100 deaths in 2012 (28). Despite the decreased mortality rate of $\mathrm{GC}$ in recent years, it is still the second leading cause of cancer-related deaths $(29,30)$. GC remains a major clinical challenge worldwide due to its poor prognosis and limited therapeutic approaches; currently, there are no effective prognostic biomarkers for GC. Accumulating studies have demonstrated that both oncogenes and anti-oncogenes play important roles in the tumorigenesis, metastasis, prognosis and drug resistance of GC (31-33). In the present study, it was reported that the absence of the tumor suppressor PLZF led to aggressive proliferation and malignant invasion of GC by inducing EMT and mechanistic methylation via the binding of ANRIL to PRC2.

In the present study, we observed that PLZF had low expression levels in the majority of GC cells and tumor tissues compared to those in the normal cell line GES1 and adjacent non-tumor tissues, respectively (Figs. 1 and 7E). Moreover, low PLZF expression in GC tissues was associated with a poor prognosis (Fig. 7F) and may be an independent prognostic factor. To determine the function of decreased PLZF expression in GC, we investigated the effects of PLZF overexpression in GC cell lines. PLZF overexpression by cDNA transfection decreased cell viability, clone formation, wound healing and cell invasion in both BGC823 and SGC7901 cells (Fig. 2). These findings indicated that decreased PLZF expression in GC contributes to GC cell proliferation and migration. In addition, in a nude mice xenograft model, SGC7901 cells with PLZF overexpression significantly inhibited tumorigenesis and had lower tumor weights, tumor sizes and $\mathrm{Ki}-67$ expression levels compared to those in the control group (Fig. 3). These effects were similar to observations in lung cancer, melanoma, prostate cancer and hepatocellular carcinoma $(7,8,34,35)$.

The lack of PLZF expression may be due to genomic alteration, epigenetic modification or a change in subcellular location. Epigenetic regulation, particularly DNA methylation, is well known as the most common contributing factor 
to a decrease in tumor suppressor functionality. Wang et al demonstrated that downregulation of PLZF in non-small cell lung cancer was partially caused by methylation of the PLZF promoter (34). Several cellular processes involve lncRNAs, and a significant number have been shown to function in cooperation with chromatin-modifying enzymes to promote epigenetic activation or silencing of gene expression (25). The first described epigenetic mechanism involving an lncRNA was Xist (X-inactive specific transcript), a product of the Xist gene, which is exclusively transcribed from the inactive $\mathrm{X}(\mathrm{Xi})$ chromosome. $\mathrm{X}$ inactivation was the first mechanism of gene silencing that was identified to depend on an interaction between IncRNA and PRC2, providing a way to study epigenetic regulation of gene expression mediated by lncRNAs (36). In the present study, lncRNA ANRIL recruited PRC2, which, in turn, EZH2, a core member of PRC2, catalyzed trimethylation of H3K27 and then drove PLZF silencing by promoting DNA methylation of PLZF. The observation that the methylation inhibitor 5-Aza can increase PLZF expression confirms regulatory methylation. There is corroborating evidence that DNA methylation is often associated with specific types of histone modifications that can cooperatively affect chromatin structure to silence gene expression (37). The methylation effect corresponds to the loss of PLZF in the differentiated GC groups in our study. These findings, at least in part, explain why PLZF expression is lost in GC.

The underlying molecular mechanism of PLZF in cancer remains poorly understood. One study in melanoma demonstrated that PLZF partially suppressed migration and invasion through integrin $\beta 3$ and MMP9 (35). We examined the expression levels of EMT markers to identify a possible mechanism and observed that PLZF overexpression decreased N-cadherin, Vimentin, Snail, Slug and ZEB1 expression levels, while it enhanced the expression level of E-cadherin, indicating that increased PLZF expression could inversely affect EMT (also called MET). Conversely, in gallbladder cancer, PLZF selectively induced the mesenchymal marker $\mathrm{N}$-cadherin, instead of vimentin and fibronectin, to initiate the MET program (11). EMT is regarded as a potent driver for cells to develop metastatic features, and the loss of PLZF initiates EMT, which contributes to the malignant development and poor prognosis of GC. These results may explain why PLZF levels are correlated with histological differentiation, tumor invasion depth, TNM stage and lymphatic metastasis. Activation of EMT has been shown to be a very efficient strategy adopted by epithelial cancer cells to promote local invasion and dissemination in distant organs (38). In the present study, the limited number of patient tissues including a limited sample of distant metastasis cases, contributed to the lack of a correlation between PLZF and distant metastasis.

Collectively, in the present study, we reported that PLZF expression was markedly reduced in GC tissues and cell lines and that the loss of PLZF expression was correlated with histological differentiation, tumor invasion depth, TNM stage, lymphatic metastasis and poor prognosis. Furthermore, we found that ANRIL expression was negatively associated with PLZF and that ANRIL recruited PRC2, which drove PLZF silencing by promoting collaboration with H3K27me3 and DNA methylation. Therefore, constitutive ANRIL activation was a possible cause of the lack of PLZF expression in GC cells. These results indicated that PLZF and ANRIL are functionally independent and that their coupled deregulation may account for most of the alterations described in GC. To the best of our knowledge, we identified the tumor-suppressor role of PLZF in GC both in vitro and in vivo, and PLZF may be a potential tumor biomarker and a critical therapeutic target for GC.

\section{Acknowledgements}

Not applicable.

\section{Funding}

This study was supported by grants from the National Natural Science Foundation of China (no. 31401094), the Natural Science Research Project of Anhui Provincial Institutions of Higher Education (no. KJ2015B118by), the Major Projects of the Natural Science Research in Anhui Provincial Colleges and Universities (grant no. KJ2018A0245), and the Nature Science Key Program of Bengbu Medical College (no. BYKY1415ZD).

\section{Availability of data and materials}

The analyzed datasets generated during the study are available from the corresponding author on reasonable request.

\section{Authors' contributions}

JBW and YJ performed the molecular studies and in vivo assays. PW and WJZ collected the clinical data and tissue samples and measured genes' expression of clinical tissues. YL performed the functional experiments and the statistical analysis. JFC and WD directed the experiments and helped draft the manuscript. FY designed the study and wrote the manuscript. All authors read and approved the manuscript and agree to be accountable for all aspects of the research in ensuring that the accuracy or integrity of any part of the work are appropriately investigated and resolved.

\section{Ethics approval and consent to participate}

The present study was approved by the Ethics Committee of Nanjing Medical University and written informed consent was obtained from all patients. All animal experiments were performed according the National Institutes of Health (Bethesda, MD, USA) guidelines on the use of experimental animals and were approved by the Ethics Committee of the Nanjing Medical University.

\section{Patient consent for publication}

Not applicable.

\section{Competing interests}

The authors declare that they have no competing interests. 


\section{References}

1. Ball HJ, Melnick A, Shaknovich R, Kohanski RA and Licht JD The promyelocytic leukemia zinc finger (PLZF) protein binds DNA in a high molecular weight complex associated with cdc2 kinase. Nucleic Acids Res 27: 4106-4113, 1999.

2. Suliman BA, Xu D and Williams BR: The promyelocytic leukemia zinc finger protein: Two decades of molecular oncology. Front Oncol 2: 74, 2012.

3. Choi WI, Kim MY, Jeon BN, Koh DI, Yun CO, Li Y, Lee CE, Oh J, Kim K and Hur MW: Role of promyelocytic leukemia zinc finger (PLZF) in cell proliferation and cyclin-dependent kinase inhibitor 1A ( $p 21 W A F / C D K N 1 A)$ gene repression. J Biol Chem 289: 18625-18640, 2014.

4. Felicetti F, Errico MC, Bottero L, Segnalini P, Stoppacciaro A Biffoni M, Felli N, Mattia G, Petrini M, Colombo MP, et al: The promyelocytic leukemia zinc finger-microRNA-221/-222 pathway controls melanoma progression through multiple oncogenic mechanisms. Cancer Res 68: 2745-2754, 2008.

5. Vincent A, Omura N, Hong SM, Jaffe A, Eshleman J and Goggins M: Genome-wide analysis of promoter methylation associated with gene expression profile in pancreatic adenocarcinoma. Clin Cancer Res 17: 4341-4354, 2011.

6. Matsuzawa K, Izawa S, Ohkura T, Ohkura H, Ishiguro K, Yoshida A, Takiyama Y, Haneda M, Shigemasa C, Yamamoto K, et al: Implication of intracellular localization of transcriptional repressor PLZF in thyroid neoplasms. BMC Endocr Disord 14: 52, 2014

7. Hsieh CL, Botta G, Gao S, Li T, Van Allen EM, Treacy DJ, Cai C, He HH, Sweeney CJ, Brown M, et al: PLZF, a tumor suppressor genetically lost in metastatic castration-resistant prostate cancer, is a mediator of resistance to androgen deprivation therapy. Cancer Res 75: 1944-1948, 2015.

8. Hui AW, Lau HW, Cao CY, Zhou JW, Lai PB and Tsui SK: Downregulation of PLZF in human hepatocellular carcinoma and its clinical significance. Oncol Rep 33: 397-402, 2015.

9. Xiao GQ, Li F, Findeis-Hosey J, Hyrien O, Unger PD, Xiao L, Dunne R, Kim ES, Yang Q, McMahon L, et al: Down-regulation of cytoplasmic PLZF correlates with high tumor grade and tumor aggression in non-small cell lung carcinoma. Hum Pathol 46: $1607-1615,2015$

10. Jin Y, Nenseth HZ and Saatcioglu F: Role of PLZF as a tumor suppressor in prostate cancer. Oncotarget 8: 71317-71324, 2017.

11. Shen H, Zhan M, Zhang Y, Huang S, Xu S, Huang X, He M, Yao Y, Man M and Wang J: PLZF inhibits proliferation and metastasis of gallbladder cancer by regulating IFIT2. Cell Death Dis 9: 71, 2018.

12. Jones C, St-Jean S, Fréchette I, Bergeron D, Rivard N and Boudreau F: Identification of a novel promyelocytic leukemia zinc-finger isoform required for colorectal cancer cell growth and survival. Int J Cancer 133: 58-66, 2013.

13. Fatica A and Bozzoni I: Long non-coding RNAs: New players in cell differentiation and development. Nat Rev Genet 15: 7-21, 2014.

14. Yap KL, Li S, Muñoz-Cabello AM, Raguz S, Zeng L, Mujtaba S, Gil J, Walsh MJ and Zhou MM: Molecular interplay of the noncoding RNA ANRIL and methylated histone $\mathrm{H} 3$ lysine 27 by polycomb CBX7 in transcriptional silencing of INK $4 a$. Mol Cell 38: 662-674, 2010.

15. Pasmant E, Laurendeau I, Héron D, Vidaud M, Vidaud D and Bièche I: Characterization of a germ-line deletion, including the entire INK4/ARF locus, in a melanoma-neural system tumor family: Identification of ANRIL, an antisense noncoding RNA whose expression coclusters with $A R F$. Cancer Res 67: 3963-3969, 2007.

16. Chen S, Zhang JQ, Chen JZ, Chen HX, Qiu FN, Yan ML, Chen YL, Peng CH, Tian YF and Wang YD: The over expression of long non-coding RNA ANRIL promotes epithelial-mesenchymal transition by activating the ATM-E2F1 signaling pathway in pancreatic cancer: An in vivo and in vitro study. Int J Biol Macromol 102: 718-728, 2017.

17. Kotake Y, Nakagawa T, Kitagawa K, Suzuki S, Liu N, Kitagawa M and Xiong Y: Long non-coding RNA ANRIL is required for the PRC2 recruitment to and silencing of $\mathrm{p} 15^{\mathrm{INK} 4 \mathrm{~B}}$ tumor suppressor gene. Oncogene 30: 1956-1962, 2011.

18. Wang J, Hevi S, Kurash JK, Lei H, Gay F, Bajko J, Su H, Sun W, Chang H, Xu G, et al: The lysine demethylase LSD1 (KDM1) is required for maintenance of global DNA methylation. Nat Genet 41: 125-129, 2009.
19. Liu X, Li C, Zhang R, Xiao W, Niu X, Ye X, Li Z, Guo Y, Tan J and Li Y: The EZH2- H3K27me3-DNMT1 complex orchestrates epigenetic silencing of the $w w c l$ gene, a Hippo/YAP pathway upstream effector, in breast cancer epithelial cells. Cell Signal 51: 243-256, 2018.

20. Long HK, King HW, Patient RK, Odom DT and Klose RJ: Protection of $\mathrm{CpG}$ islands from DNA methylation is DNA-encoded and evolutionarily conserved. Nucleic Acids Res 44: 6693-6706, 2016.

21. Nawaz I, Qiu X, Wu H, Li Y, Fan Y, Hu LF, Zhou Q and Ernberg I: Development of a multiplex methylation specific PCR suitable for (early) detection of non-small cell lung cancer. Epigenetics 9: 1138-1148, 2014.

22. Livak KJ and Schmittgen TD: Analysis of relative gene expres-

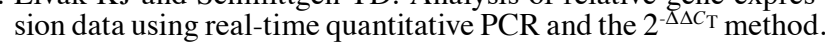
Methods 25: 402-408, 2001.

23. Chen JF, Wu P, Xia R, Yang J, Huo XY, Gu DY, Tang CJ, De W and Yang F: STAT3-induced lncRNA HAGLROS overexpression contributes to the malignant progression of gastric cancer cells via mTOR signal-mediated inhibition of autophagy. Mol Cancer 17: 6, 2018.

24. Yang F, Deng R, Qian XJ, Chang SH, Wu XQ, Qin J, Feng GK, Ding K and Zhu XF: Feedback loops blockade potentiates apoptosis induction and antitumor activity of a novel AKT inhibitor DC120 in human liver cancer. Cell Death Dis 5: e1114, 2014.

25. Marchese FP and Huarte M: Long non-coding RNAs and chromatin modifiers: Their place in the epigenetic code. Epigenetics 9: 21-26, 2014.

26. Cech TR and Steitz JA: The noncoding RNA revolution-trashing old rules to forge new ones. Cell 157: 77-94, 2014.

27. Huang MD, Chen WM, Qi FZ, Xia R, Sun M, Xu TP, Yin L, Zhang EB, De W and Shu YQ: Long non-coding RNA ANRIL is upregulated in hepatocellular carcinoma and regulates cell apoptosis by epigenetic silencing of KLF2. J Hematol Oncol 8: $50,2015$.

28. Colquhoun A, Arnold M, Ferlay J, Goodman KJ, Forman D and Soerjomataram I: Global patterns of cardia and non-cardia gastric cancer incidence in 2012. Gut 64: 1881-1888, 2015.

29. Siegel RL, Miller KD and Jemal A: Cancer statistics, 2018. CA Cancer J Clin 68: 7-30, 2018.

30. Chen W, Zheng R, Baade PD, Zhang S, Zeng H, Bray F, Jemal A, Yu XQ and He J: Cancer statistics in China, 2015. CA Cancer J Clin 66: 115-132, 2016.

31. Chia NY, Deng N, Das K, Huang D, Hu L, Zhu Y, Lim KH, Lee MH, Wu J, Sam XX, et al: Regulatory crosstalk between lineage-survival oncogenes KLF5, GATA4 and GATA6 cooperatively promotes gastric cancer development. Gut 64: 707-719, 2015.

32. Thiem S, Eissmann MF, Elzer J, Jonas A, Putoczki TL, Poh A, Nguyen P, Preaudet A, Flanagan D, Vincan E, et al: Stomach-specific activation of oncogenic KRAS and STAT3-dependent inflammation cooperatively promote gastric tumorigenesis in a preclinical model. Cancer Res 76: 2277-2287, 2016.

33. Wang K, Liang Q, Li X, Tsoi H, Zhang J, Wang H, Go MY, Chiu PW, Ng EK, Sung JJ and Yu J: MDGA2 is a novel tumour suppressor cooperating with DMAP1 in gastric cancer and is associated with disease outcome. Gut 65: 1619-1631, 2016.

34. Wang X, Wang L, Guo S, Bao Y, Ma Y, Yan F, Xu K, Xu Z, Jin L, Lu D, et al: Hypermethylation reduces expression of tumor-suppressor PLZF and regulates proliferation and apoptosis in non-small-cell lung cancers. FASEB J 27: 4194-4203, 2013.

35. Felicetti F, Bottero L, Felli N, Mattia G, Labbaye C, Alvino E, Peschle C, Colombo MP and Carè A: Role of PLZF in melanoma progression. Oncogene 23: 4567-4576, 2004.

36. Khalil AM, Guttman M, Huarte M, Garber M, Raj A, Rivea Morales D, Thomas K, Presser A, Bernstein BE, van Oudenaarden A, et al: Many human large intergenic noncoding RNAs associate with chromatin-modifying complexes and affect gene expression. Proc Natl Acad Sci USA 106: 11667-11672, 2009.

37. Nguyen CT, Gonzales FA and Jones PA: Altered chromatin structure associated with methylation-induced gene silencing in cancer cells: Correlation of accessibility, methylation, MeCP2 binding and acetylation. Nucleic Acids Res 29: 4598-4606, 2001.

38. Ombrato L and Malanchi I: The EMT universe: Space between cancer cell dissemination and metastasis initiation. Crit Rev Oncog 19: 349-361, 2014. 